\title{
Examining life-course influences on chronic disease: the importance of birth cohort studies from low- and middle- income countries. An overview
}

\section{G.D. Batty ${ }^{1}$, \\ J.G. Alves ${ }^{2}$, \\ J. Correia ${ }^{2}$ and \\ D.A. Lawlor ${ }^{3}$}

\author{
${ }^{1} \mathrm{MRC}$ Social and Public Health Sciences Unit, University of Glasgow \\ Glasgow, UK \\ ${ }^{2}$ Instituto Materno Infantil Prof. Fernando Figueira, Recife, PE, Brasil \\ ${ }^{3}$ Department of Social Medicine, University of Bristol, Bristol, UK
}

\author{
Correspondence \\ G.D. Batty \\ MRC Social \& Public Health \\ Sciences Unit \\ 4 Lilybank Gardens \\ Glasgow \\ UK G12 8RZ \\ Fax: +44-141-337-2389 \\ E-mail: david-b@msoc.mrc.gla.ac.uk \\ G.D. Batty is a Wellcome Trust fellow. \\ D.A. Lawlor is supported by a \\ Department of Health (UK) \\ Career Scientist Award. \\ $\ldots \ldots \ldots \ldots \ldots \ldots \ldots$
}

Received August 3, 2007

Accepted August 21, 2007

\section{Abstract}

The objectives of this overview are to describe the past and potential contributions of birth cohorts to understanding chronic disease aetiology; advance a justification for the maintenance of birth cohorts from low- and middle-income countries (LMIC); provide an audit of birth cohorts from LMIC; and, finally, offer possible future directions for this sphere of research. While the contribution of birth cohorts from affluent societies to understanding disease aetiology has been considerable, we describe several reasons to anticipate why the results from such studies might not be directly applied to LMIC. More than any other developing country, Brazil has a tradition of establishing, maintaining and exploiting birth cohort studies. The clear need for a broader geographical representation may be precipitated by a greater collaboration worldwide in the sharing of ideas, fieldwork experience, and cross-country cohort data comparisons in order to carry out the best science in the most efficient manner. This requires the involvement of a central overseeing body - such as the World Health Organization - that has the respect of all countries and the capacity to develop strategic plans for 'global' life-course epidemiology while addressing such issues as data-sharing. For rapid progress to be made, however, there must be minimal bureaucratic entanglements.

\section{Introduction}

Rates of non-communicable diseases such as cardiovascular disease (CVD) and many malignancies are declining in most industrialised countries; however, they remain the leading causes of death (1). Whilst inadequate infrastructure in some countries makes
Key words

- Birth cohort

- Chronic disease

- Developing country

- Epidemiology

- Life-course 
has been highlighted (4), what is often ignored in considering such statistics is the impact of less lethal, but nonetheless debilitating diseases such as psychiatric illness: by the same year it is estimated that clinical depression will become the number one cause of disability-adjusted life years in developing societies (3). The added presence of communicable diseases - HIV/AIDS, malaria, tuberculosis, acute respiratory infections, diarrheal disease and other vaccinepreventable illnesses - and, in women, serious obstetric complications, has raised welldocumented concerns of a dual burden of disease amongst the world's poor.

A large number of studies using observational designs (chiefly cohort and case-control), representing a research tradition beginning in the 1940s America (5), have been conducted in middle- and older-aged persons in high-income countries. These have offered crucial insights into understanding the aetiology of non-communicable diseases. Notable examples include work pioneered by Doll et al. $(6,7)$ that identified the link between cigarette smoking and lung cancer, heart disease and other adverse health outcomes, and, more recently, studies establishing the causal associations of both high blood pressure (8) and dyslipidemia (9) with CVD. These findings have been instrumental in the development of interventions (lifestyle and pharmacological) that have resulted in population-level declines in these risk factors, treatment of those at highest risk, and ultimately decreases in CVD morbidity and mortality rates.

Despite these successes, there are debates about the extent to which these now established, major adult risk factors, when measured solely in mid-life, fully explain the variation in important chronic diseases, such as CVD $(10,11)$. Some investigators have argued that these risk factors explain most of the geographical and secular variations in non-communicable diseases, such as CVD, and that there is no need to search further (12). However, this focus on adult risk factors, which is consistent with a degenerative model of non-communicable disease epidemiology, pays scant attention to processes that lead up to the peak or optimal phenotypic states that are usually a feature of adolescence or early adulthood, and that are increasingly recognised as relevant to non-communicable disease risk in adulthood. In humans, these optimal phenotypic states include peak bone mass (usually attained post-puberty), peak respiratory function (usually attained in the early 20s), and peak arterial function (usually attained by the age of 15-20 years). This more recent approach to understanding disease processes thus recognises the development of anatomical and physiological systems, in addition to how rapidly one degenerates from this optimum, as having important relevance to the occurrence of non-communicable diseases.

\section{A life-course approach to risk factor identification}

Support for the importance of developmental processes in the aetiology of adult non-communicable diseases, particularly CVD, can be found in studies employing diverse research designs. First, pathological investigations have revealed evidence of atherosclerosis - the precursor to coronary heart disease - in males as young as 15 years of age (13). Second, levels of established mid-life risk factors for selected cancers and CVD (physical inactivity, raised blood pressure, obesity, etc.) seem to 'track' between childhood and adulthood, such that children at high risk tend to become adults at high risk (14). Third, for adult-targeted lifestyle modification designed to reduce coronary heart disease rates, results are typically modest (15), suggesting that earlier intervention may have some benefit. Finally, in a small but growing literature, several of the classic markers of disease risk identified in adult populations - smoking, raised blood pres- 
sure, obesity - also seem to be predictive of later CVD and cancer risk when measured in younger populations who are followed into middle- and older-age (16). These findings have been derived from cohort studies, sometimes birth cohort studies, which are the focus of the present issue of the Brazilian Journal of Medical and Biological Research which features a series of reports from the Ribeirão Preto and São Luís cohorts.

A birth cohort study can be defined as the collection of data at follow-up survey, through passive (that is, routinely collected information; e.g., hospital admissions, death registration or educational records) and/or active (e.g., medical examination) means, of a group of individuals born around the same time (this may stretch to a few days, or, in some studies, years) over a given period (often decades). In Latin, cohors refers to a group of warriors within a Roman legion (17). Alternative terms for cohort study include longitudinal or panel study. These investigations are also sometimes referred to as pregnancy cohorts or family cohorts, recognising that for some (e.g., Avon Longitudinal Study of Parents and Children (18) and Mater-University of Queensland Study of Pregnancy (19)) recruitment was of mothers in early pregnancy - sometimes by identifying those who were seeking to become pregnant. Using this approach, information on parents and children is gathered during the follow-up period. Such studies differ from many birth cohorts (e.g., UK 1946, 1958) that recruited infants at birth in that they are better able to evaluate the role of (intrauterine) exposures such as maternal diet, smoking and alcohol consumption on both the future health of the index child (socalled trans-generational or intergenerational influences) and the mother. That cohort studies may utilise retrospective and/or prospective data collection is essentially irrelevant though overemphasised by some - as the logic of any association is always forward.

Prompted by this body of work pointing to the importance of both developmental and degenerative processes in the aetiology of adult disease, a "life-course" paradigm has been proposed which offers a framework for identifying the long-term effect on adult disease of social, physiological, behavioural, and psychological processes operating during gestation, childhood, adolescence, adulthood, and between generations (20). This approach therefore emphasises a combination of measures of developmental and degenerative processes from across the life span and, ideally, between generations. The last two decades have witnessed a marked rise in research output in this area as evidenced by the increasing number of publications over the last 20 years citing the use of birth cohort studies on which much of the understanding of life-course influences on health is based (Figure 1).

\section{Contribution of birth cohorts from high-income countries}

To date, much of what is known about the developmental origins of adult disease has been gleaned from cohort studies based on

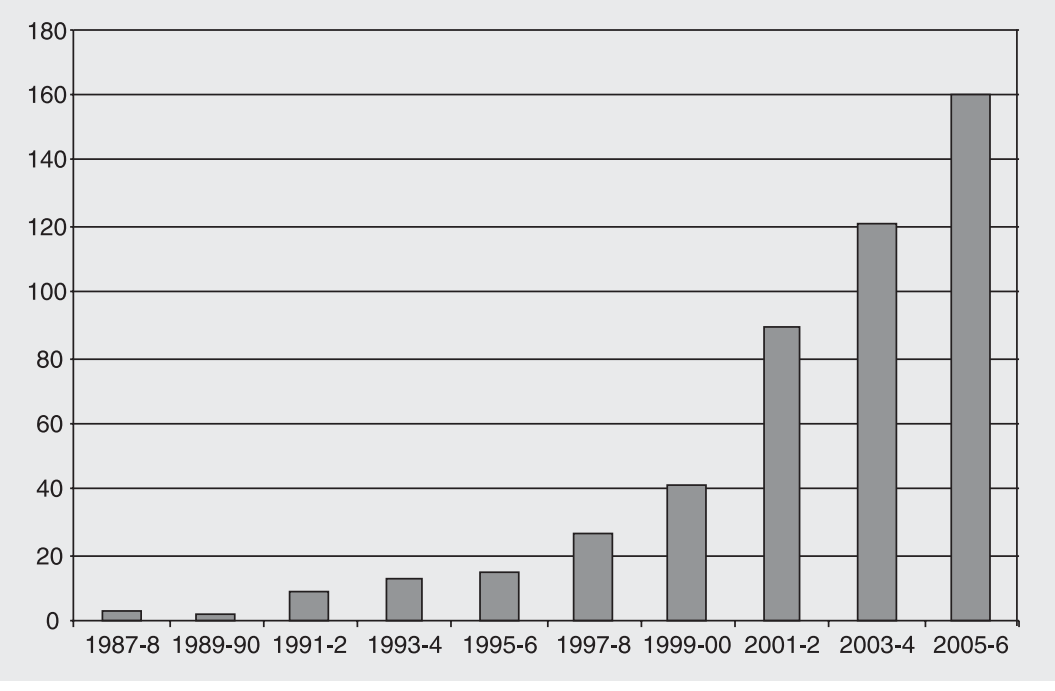

Figure 1. Number of publications referring to birth cohort studies in the last 20 years (19852006). Based on a search of the PubMed database (http://www.ncbi.nlm.nih.gov/sites/ entrez?db=PubMed) for any article containing the terms "birth cohort study" or "birth-cohort study"; no language restrictions. 
high-income countries (for examples, see Table 1). This is largely the product of affluence which manifests itself in several ways. First, these societies have the medical research funding to facilitate the initiation and maintenance of cohorts. Second, births typically occur in hospitals, rather than the home, and home visits by a medical practitioner during infancy (often with routine collection of standard data on growth and development) are commonplace, thus facilitating systematic documentation of early life characteristics. Third, surveillance of cohort members is less problematic than in non-industrialised countries owing to a lower prevalence of internal (rural to urban) migration and the capacity to trace persons passively through national databases. This is particularly evident in the Scandinavian countries where unique person identification numbers have expedited the process (see for example, reports based on Swedish (21-23) and Danish $(24,25)$ population-based studies).

These cohorts, together with basic sci- ence studies, have contributed to an increased understanding of the developmental origins of non-communicable diseases. There have been replicated associations of measures of growth in utero and post-natally with CVD and type 2 diabetes $(26,27)$; childhood and life-course socio-economic adversity with CVD, diabetes, selected cancers, psychiatric illnesses and trauma in adulthood (28), and exposures around the time of pubertal development with hormone-related cancers (29). More recently, low mental ability (IQ) in childhood has been shown to be related to an elevated risk of subsequent all-cause mortality, CVD and some psychiatric illnesses (24, 30). However, the mechanisms underlying some of these associations are unclear and sometimes difficult to interpret $(31,32)$. The relationship between measures of intrauterine growth and postnatal growth with adult disease is a pertinent example. Even if it is accepted that these associations are not fully explained by statistical artefact or confound-

Table 1. Birth cohort studies from economically developed and developing countries.

\begin{tabular}{|c|c|c|c|}
\hline Name key citation & Location & Birth years(s) & Cohort size at induction* \\
\hline \multicolumn{4}{|l|}{ High-income countries } \\
\hline British Cohort Studies (63-67) & UK & $1946,1958,1970, \sim 2000$ & Range: $5362-20,000$ \\
\hline Avon Longitudinal Study of Parents and Children $(18,68)$ & England & $1991 / 2$ & 13,971 \\
\hline Aberdeen Children of the 1950 s Study $(34,69)$ & Scotland & $1950-6$ & 12,150 \\
\hline Northern Finland Birth Cohort (48) & Finland & 1966 & 12,058 \\
\hline Danish National Birth Cohort (70) & Denmark & $1997-2003$ & Births to 100,000 women** \\
\hline National Collaborative Perinatal Project (71) & US (selected sites active) & $1959-66$ & 633 \\
\hline Dunedin Multidisciplinary Health and Development Study (72) & New Zealand & $1972 / 73$ & 1037 \\
\hline Mater-University of Queensland Study of Pregnancy (19) & Australia & $1981 / 84$ & 7223 \\
\hline \multicolumn{4}{|l|}{ Low- and middle-income countries } \\
\hline South Dehi Cohort (43) & India & 1969-72 & 8181 \\
\hline Human Capital Study (73) & Guatemala & 1969-77 & 1301 \\
\hline 1982 Pelotas Birth Cohort Study $(41,74)$ & Brazil & 1982 & 5914 \\
\hline 1993 Pelotas Birth Cohort Study (74) & Brazil & 1993 & 5249 \\
\hline 2004 Pelotas Birth Cohort Study (74) & Brazil & 2004 & 2403 \\
\hline 1978/79 Ribeirão Preto Birth Cohort Study $(75,76)$ & Brazil & $1978 / 79$ & 6827 \\
\hline 1994 Ribeirão Preto Birth Cohort Study (76) & Brazil & 1994 & 2846 \\
\hline 1997/98 São Luís Birth Cohort Study (76) & Brazil & $1997 / 98$ & 2443 \\
\hline Cebu cohort $(77,78)$ & Philippines & $1983 / 84$ & 2080 \\
\hline Birth to Twenty Cohort (60-62) & South Africa & 1990 & 3273 \\
\hline
\end{tabular}

Only cohorts with over 1000 study participants at induction and for which investigators continue to be research active were included in this table. The cited cohorts from high-income countries is illustrative of those available but not exhaustive, while the cited cohorts from low- and middleincome countries is intended to be fully comprehensive. ${ }^{*}$ Cohort size occasionally varies across publications. ${ }^{* *}$ Projected recruitment. 
ing, it is difficult to envisage a biological process by which growth per se during the developmental period has a direct impact on later disease outcomes. A more plausible explanation is that exposures, including genetic, environmental and epigenetic, that influence growth during development also increase adult disease risk. Understanding the nature of these exposures is key to preventing disease and improving health.

Whilst the contribution made by birth cohorts in high-income countries to clarifying the developmental origins of adult disease is marked, and notwithstanding the need for further research in this area, it is notable that, even with substantial resources and a supportive infrastructure, maintaining birth/ pregnancy cohorts is problematic. Some of the most important findings from such cohorts are only likely to emerge seven or more decades after they begin. This is because studies that can really contribute to understanding how risk factors that influence developmental processes combine with those affecting degenerative processes to impact upon disease risk require cohorts that have collected repeat, detailed information from the parental generation, through gestation, childhood, adolescence and early adulthood to the point at which non-communicable diseases are common. Over this time, loss to follow-up, even in high-income countries, is likely to be considerable. For example, in a 53-year follow-up of the 5362 infants in the 1946 UK birth cohort only 2977 cohort members (55\%) provided information (33); this is broadly in keeping with the response in other birth cohort studies (34). Birth cohort studies require funding bodies and researchers who are willing to not only commit to an investigation for some decades, but also to accept delayed gratification that realistically extends into the next generation of scientists. They also require resources to develop field methods for maximising participant uptake and for the development of analytical methods for de- termining the extent to which attrition might bias findings, a perennial problem in cohort studies.

\section{Why should funding bodies support existing and future birth cohort studies in LMIC?}

Given some of the described difficulties of establishing and maintaining birth cohorts, together with the likelihood that several risk factors may well be equally important in both industrialised societies and LMIC, one could argue that limited research funds should be directed towards studies that evaluate population-specific interventions aimed at reduction of risk factors for important non-communicable disease in LMIC (e.g., smoking prevention programs, interventions for improving antenatal care, re-housing studies). While this approach has its obvious merits, we believe that there are several important reasons for supporting birth cohorts in LMIC.

First, there are fundamental differences in the composition of important exposures across countries. For example, in industrialised societies, most physical activity in children and adults is accumulated in leisure where it is vigorous and time-limited. By contrast, in LMIC, energy expenditure is largely occupational in nature or produced whilst undertaking essential activities of daily living (including transportation) where it is typically of longer duration but of lower intensity. Similarly, while tobacco consumption in western populations mainly comprises inhalation from cigarettes, in South Asia over one-third of tobacco intake is smokeless (35). The consumption of traditional forms such as betel quid, tobacco with lime, and tobacco tooth powder is increasing. Further, when tobacco smoke is inhaled, 'bidis' are more common than cigarettes in selected countries such as India. Although smaller than cigarettes, bidis potentially deliver a higher dose of cancercausing agents (36). In a further example, 
infants who are not breast-fed in high-income countries will typically receive formula replacement, whereas the principal substitute in LMIC is often cow's milk. Of relevance to the developmental origins of disease, there is some evidence that body composition for a given birth size differs between English and Indian infants, with evidence that the so-called 'fat-thin insulinresistant' phenotype common in south Asian adults (37-39) may be present at birth (40). In these various instances, comparison of the exposed and unexposed with respect to a given health endpoint may give rise to different findings in samples drawn from different countries (41). These differences might provide important etiological insights of benefit to individuals from all populations.

Second, the confounding structure of a given variable may differ in LMIC. Taking the example of breast feeding again, while this practice is more common in affluent groups from high-income countries, the reverse is the case in developing societies. Given that, in keeping with other behaviours, breast feeding is a highly confounded variable (42), this is a crucial issue in considering its relation to health outcomes. The occurrence of consistent findings for a given association across high-income and LMIC, despite differential confounding structures, would minimise concerns that confounding is an important alternative explanation.

Third, while the relation of foetal and postnatal growth with adult disease has, with some exceptions (43), been examined in most detail in cohorts drawn from affluent societies - in particular the Hertfordshire (UK) (44) and Helsinki (Finland) (45) historical cohorts (Table 1) - the findings may have most relevance for LMIC where the higher prevalence of low birth weight, malnutrition and stunting result in greater population attributable risk. However, as discussed, the possible difference in body composition at a given birth weight, and the uncertainty about the biological pathways that link low birth weight and stunted early postnatal growth to later disease outcomes, emphasises the importance of first establishing whether growth parameters during developmental periods relate to adult noncommunicable disease outcomes in LMIC in the same way that they do in high-income countries.

Fourth, there are some exposures that are relatively unique in LMIC and that might have important influences on developmental and degenerative processes leading to illhealth. For example, cancer-causing occupational exposures, such as benzene (46), are more common in non-industrialised societies where conditions of occupational hygiene will probably be less favourable than in high-income countries (47). The same may be true of wider environmental pollutants, such as pesticides (48). Such exposures might have lasting influences across generations via an intrauterine effect where women of reproductive age are exposed. Developing a robust evidence base of the health effects of such exposures is likely to be important in supporting policy aimed at maintaining economic growth that is not at the expense of population health.

Fifth, socio-economic inequalities in health outcomes, such as coronary heart disease, appear to differ by epoch in western societies (49). Similarly, they are also likely to vary by country at a single point in time. A recent cross-country comparison of socioeconomic variation in insulin resistance in European children (50) serves as a reminder of this. In a more affluent country (Denmark), higher socio-economic position, as indexed by family income and education, was associated with lower (more favourable) insulin levels, while in countries undergoing marked social, cultural, and economic transition (Portugal and, particularly, Estonia) the association was positive (50). The authors speculated that, in the countries undergoing economic upheaval, life style changes attributable to globalisation and urbanisation - including a movement from a diet rich in 
complex carbohydrate and fibre to one in which sugars and fats predominate - may be occurring. That such changes impact most rapidly upon affluent individuals in countries experiencing such transitions might explain the results.

Finally, the replication of established risk factor-disease relationships in LMIC may have important, positive political ramifications. For example, it has been speculated that the absence of specific data for LMIC has led to the importance of cigarette smoking as a major cause of death being seriously underestimated by the medical profession, the media and government in those countries (4). It has been claimed, for example, that smoking, a well-established risk factor for CVD in developed nations (see earlier), may be less detrimental to CVD outcomes in east Asian countries where cholesterol levels are low (51). This myth may at least partially explain the very high smoking rates amongst men in particular in these countries (51). It is hoped that recent analyses of large cohorts drawn from, for instance, China (52) and Korea (53), that clearly counter this standpoint, together with worrying predictions of future deaths (2), will bring about a change in political will. Thus, even in the absence of biological plausibly for a different exposure-disease relation, it may be important to replicate in LMIC what most epidemiologists would consider an established association. This also has much relevance to birth cohort studies: smoking is often initiated in adolescence or early adulthood, and a lifecourse approach using birth cohort data should be useful in exploring the country- or population-specific early life predictors of this behaviour (i.e., the determinants of the disease determinants).

\section{Existing birth cohorts in LMIC}

In Table 1 we describe a series of birth cohort studies from LMIC that have already contributed towards the understanding of chronic disease aetiology, or have the potential to do so. For the purposes of comparison, we also list some birth cohort studies from high-income countries. Our criteria for including studies were that they should have recruited at least 1000 participants and that, to our knowledge, they remain research active (i.e., still publishing and/or collecting follow-up data on participants). The list of cohorts from LMIC is - we hope - exhaustive, while several cohorts from high-income nations could not be included owing to page constraints (thus, these examples are illustrative rather than exhaustive). Unsurprisingly, for reasons already stated, in comparison to cohorts from high-income societies, those from LMIC are fewer in number, generally smaller in size, and less mature; however, in general, they offer similarly detailed and valuable data.

It is perhaps inevitable that, given their characteristics, other LMIC birth cohorts are compared with the three Pelotas (Brazil) studies (established in 1982, 1993, 2004) from which a series of publications have resulted $(54,55)$ (for a more comprehensive listing, see a recent profile of the study (41)). These cohorts have probably contributed more to the knowledge base in non-industrialised countries than any other from a similar society. Important factors in the continued successful follow-up of the Pelotas study participants have been the moderate size of the city which makes data collection manageable (while maintaining a reasonable level of statistical power); rates of inand out-migration that are below the national average, and, perhaps crucially, fewer apparent concerns of the inhabitants over personal safety, so common elsewhere is Brazil, resulting in refusal to participate being rare (41). The relative affluence of the city of Pelotas is comparable with that of Ribeirão Preto (cohorts established in 1978/ 79 and 1994). Importantly, in 1997/98, using the same methodology, some of the original Ribeirão Preto cohort investigators es- 
tablished the São Luís cohort based on the socio-economically disadvantaged north of Brazil.

Another important feature of Table 1 is that it highlights the regions of the world with few or no birth cohorts. Unrepresented are: east Asia, north Africa, the Middle East, and the former Soviet Union, a country where social upheaval and major problems with substance abuse in adults (56-59) are likely to impact upon the development of future generations. To our knowledge, there is also only one birth cohort in south Asia (43), a region where there are likely to be marked differences in exposures and developmental processes across different countries. Similarly, there is only one birth cohort in subSaharan Africa (60-62).

\section{Future directions}

We have, we hope, provided some pertinent reasons for supporting existing and new birth cohorts in LMIC. The clear need for a broader geographical representation may be precipitated by a greater collaboration worldwide in the sharing of ideas, fieldwork experience, cross-country cohort comparisons, and data, in order to carry out the best science in the most efficient manner. This re- quires the involvement of a central overseeing body - such as the World Health Organization (WHO) - that has the respect of all countries and the capacity to develop strategic plans for 'global' life-course epidemiology while addressing such issues as datasharing. For rapid progress to be made, however, there must be minimal bureaucratic entanglements. An agency such as the WHO should also be mindful of the worrying potential of, and anecdotal evidence for, research 'neo-colonialisation'. That is, the practice by some investigators of 'parachuting in' to collect data in LMIC in the absence of full collaboration with existing researchers. Research resources, in their broadest sense, have to be about building local research capacity in LMIC.

\section{Acknowledgments}

Part of this manuscript was written while David Batty was a visiting fellow at Instituto Materno Infantil Prof. Fernando Figueira (IMIP), Recife, PE, Brazil. The views expressed in this publication are those of the authors and not necessarily those of any funding body. The authors would welcome any additions to studies from LMIC (Table 1) if omissions have been made.

\section{References}

1. Anonymous. Mortality statistics: cause, 1995. London: The Stationery Office; 1997.

2. Murray CJ, Lopez AD. Mortality by cause for eight regions of the world: Global Burden of Disease Study. Lancet 1997; 349: 12691276.

3. Murray CJ, Lopez AD. The global burden of disease. Boston: WHO, Harvard School of Public Health, World Bank; 1996.

4. Ebrahim S, Smeeth L. Non-communicable diseases in low and middle-income countries: a priority or a distraction? Int J Epidemiol 2005; 34: 961-966.

5. Dawber TR, Meadors GF, Moore FE Jr. Epidemiological approaches to heart disease: the Framingham Study. Am J Public Health Nations Health 1951; 41: 279-281.

6. Doll R, Bradford Hill A. Smoking and carcinoma of the lung; preliminary report. Br Med J 1950; 2: 739-748.

7. Doll R, Peto R, Boreham J, Sutherland I. Mortality from cancer in relation to smoking: 50 years observations on British doctors. $\mathrm{Br} \mathrm{J}$ Cancer 2005; 92: 426-429.

8. MacMahon S, Peto R, Cutler J, Collins R, Sorlie P, Neaton J, et al. Blood pressure, stroke, and coronary heart disease. Part 1, Prolonged differences in blood pressure: prospective observational studies corrected for the regression dilution bias. Lancet 1990; 335: 765-774.

9. Stamler J, Wentworth D, Neaton JD. Is relationship between serum cholesterol and risk of premature death from coronary heart disease continuous and graded? Findings in 356,222 primary screenees of the Multiple Risk Factor Intervention Trial (MRFIT). JAMA 1986; 256: 2823-2828.

10. Marmot MG, Shipley MJ, Rose G. Inequalities in death - specific explanations of a general pattern? Lancet 1984; 1: 1003-1006.

11. Batty GD, Der G, Macintyre S, Deary IJ. Does IQ explain socioeconomic inequalities in health? Evidence from a population based 
cohort study in the west of Scotland. BMJ 2006; 332: 580-584.

12. Magnus $\mathrm{P}$, Beaglehole $\mathrm{R}$. The real contribution of the major risk factors to the coronary epidemics: time to end the "only-50\%" myth. Arch Intern Med 2001; 161: 2657-2660.

13. Enos WF, Holmes RH, Beyer J. Coronary disease among United States soldiers killed in action in Korea; preliminary report. $J \mathrm{Am}$ Med Assoc 1953; 152: 1090-1093.

14. Andersen LB. Tracking of risk factors for coronary heart disease from adolescence to young adulthood with special emphasis on physical activity and fitness. A longitudinal study. Dan Med Bull 1996; 43: 407-418.

15. Ebrahim S, Davey Smith G. Systematic review of randomised controlled trials of multiple risk factor interventions for preventing coronary heart disease. BMJ 1997; 314: 1666-1674.

16. McCarron P, Davey Smith G. Physiological measurements in children and young people, and risk of coronary heart disease in adults. In: Gates A (Editor), A lifecourse approach to coronary heart disease prevention scientific and policy review. London: The Stationery Office; 2003. p 49-78.

17. Last J. A dictionary of epidemiology. Oxford: Oxford University Press; 1995.

18. Golding J, Pembrey M, Jones R. ALSPAC - the Avon Longitudinal Study of Parents and Children. I. Study methodology. Paediatr Perinat Epidemiol 2001; 15: 74-87.

19. Najman JM, Bor W, O'Callaghan M, Williams GM, Aird R, Shuttlewood G. Cohort profile: the Mater-University of Queensland Study of Pregnancy (MUSP). Int J Epidemiol 2005; 34: 992-997.

20. Kuh D, Ben Shlomo Y. A lifecourse approach to chronic disease epidemiology. Oxford: Oxford Medical Publications; 2004.

21. Lawlor DA, Hubinette A, Tynelius P, Leon DA, Davey Smith G, Rasmussen $F$. Associations of gestational age and intrauterine growth with systolic blood pressure in a family-based study of 386,485 men in 331,089 families. Circulation 2007; 115: 562-568.

22. Lawlor DA, Sterne JA, Tynelius P, Davey Smith G, Rasmussen F. Association of childhood socioeconomic position with cause-specific mortality in a prospective record linkage study of 1,839,384 individuals. Am J Epidemiol 2006; 164: 907-915.

23. Batty GD, Wennerstad KM, Davey Smith G, Gunnell D, Deary IJ, Tynelius $\mathrm{P}$, et al. IQ in early adulthood and later cancer risk: cohort study of one million Swedish men. Ann Oncol 2007; 18: 21-28.

24. Batty GD, Mortensen EL, Osler M. Childhood IQ in relation to later psychiatric disorder: evidence from a Danish birth cohort study. Br J Psychiatry 2005; 187: 180-181.

25. Batty GD, Mortensen EL, Nybo Andersen AM, Osler M. Childhood intelligence in relation to adult coronary heart disease and stroke risk: evidence from a Danish birth cohort study. Paediatr Perinat Epidemiol 2005; 19: 452-459.

26. Barker DJ. Mothers, babies and health in later life. Churchill Livingstone: Edinburgh; 1998.

27. Lawlor DA, Davey Smith G, Clark H, Leon DA. The associations of birthweight, gestational age and childhood BMI with type 2 diabetes: findings from the Aberdeen Children of the 1950s cohort. Diabetologia 2006; 49: 2614-2617.

28. Galobardes B, Lynch JW, Davey Smith G. Childhood socioeconomic circumstances and cause-specific mortality in adulthood: systematic review and interpretation. Epidemiol Rev 2004; 26: 7-21.

29. Lipworth L. Epidemiology of breast cancer. Eur J Cancer Prev 1995; 4: 7-30.

30. Batty GD, Deary IJ, Gottfredson LS. Premorbid (early life) IQ and later mortality risk: systematic review. Ann Epidemiol 2007; 17: 278288.
31. Huxley R, Neil A, Collins R. Unravelling the fetal origins hypothesis: is there really an inverse association between birthweight and subsequent blood pressure? Lancet 2002; 360: 659-665.

32. Lawlor DA, Leon DA, Rasmussen F. Growth trajectory matters: interpreting the associations among birth weight, concurrent body size, and systolic blood pressure in a cohort study of 378,707 Swedish men. Am J Epidemiol 2007; 165: 1405-1412.

33. Hardy R, Lawlor DA, Black S, Wadsworth ME, Kuh D. Number of children and coronary heart disease risk factors in men and women from a British birth cohort. BJOG 2007; 114: 721-730.

34. Batty GD, Morton SM, Campbell D, Clark H, Davey Smith G, Hall M, et al. The Aberdeen Children of the 1950s cohort study: background, methods and follow-up information on a new resource for the study of life course and intergenerational influences on health. Paediatr Perinat Epidemiol 2004; 18: 221-239.

35. Gupta PC, Ray CS. Smokeless tobacco and health in India and South Asia. Respirology 2003; 8: 419-431.

36. Vineis $\mathrm{P}$, Alavanja M, Buffler $\mathrm{P}$, Fontham E, Franceschi $\mathrm{S}$, Gao YT, et al. Tobacco and cancer: recent epidemiological evidence. $J$ Natl Cancer Inst 2004; 96: 99-106.

37. McKeigue PM, Shah B, Marmot MG. Relation of central obesity and insulin resistance with high diabetes prevalence and cardiovascular risk in South Asians. Lancet 1991; 337: 382-386.

38. Ramachandran A, Snehalatha C, Dharmaraj D, Viswanathan M. Prevalence of glucose intolerance in Asian Indians. Urban-rural difference and significance of upper body adiposity. Diabetes Care 1992; 15: 1348-1355.

39. Yajnik CS, Yudkin JS. The Y-Y paradox. Lancet 2004; 363: 163.

40. Yajnik CS, Lubree HG, Rege SS, Naik SS, Deshpande JA, Deshpande SS, et al. Adiposity and hyperinsulinemia in Indians are present at birth. J Clin Endocrinol Metab 2002; 87: 5575-5580.

41. Victora CG, Barros FC. Cohort profile: the 1982 Pelotas (Brazil) birth cohort study. Int J Epidemiol 2006; 35: 237-242.

42. Batty GD, Der G, Deary IJ. Effect of maternal smoking during pregnancy on offspring's cognitive ability: empirical evidence for complete confounding in the US national longitudinal survey of youth. Pediatrics 2006; 118: 943-950.

43. Bhargava SK, Sachdev HS, Fall CH, Osmond C, Lakshmy R, Barker DJ, et al. Relation of serial changes in childhood body-mass index to impaired glucose tolerance in young adulthood. N Engl J Med 2004; 350: $865-875$

44. Syddall HE, Aihie SA, Dennison EM, Martin HJ, Barker DJ, Cooper C. Cohort profile: the Hertfordshire cohort study. Int $J$ Epidemiol 2005; 34: 1234-1242.

45. Eriksson JG. Epidemiology, genes and the environment: lessons learned from the Helsinki Birth Cohort Study. J Intern Med 2007; 261: 418-425

46. Hayes RB, Yin SN, Dosemeci M, Li GL, Wacholder S, Chow WH, et al. Mortality among benzene-exposed workers in China. Environ Health Perspect 1996; 104 (Suppl 6): 1349-1352.

47. Stewart BW, Coates AS. Cancer prevention: a global perspective. $J$ Clin Oncol 2005; 23: 392-403.

48. Rantakallio $P$. The longitudinal study of the northern Finland birth cohort of 1966. Paediatr Perinat Epidemiol 1988; 2: 59-88.

49. Marmot MG, Adelstein AM, Robinson N, Rose GA. Changing socialclass distribution of heart disease. Br Med J 1978; 2: 1109-1112.

50. Lawlor DA, Harro M, Wedderkopp N, Andersen LB, Sardinha LB, Riddoch CJ, et al. Association of socioeconomic position with insulin resistance among children from Denmark, Estonia, and Portugal: cross sectional study. BMJ 2005; 331: 183.

51. Anonymous. The tobacco atlas. Geneva: World Health Organiza- 
tion; 2002

52. Liu BQ, Peto R, Chen ZM, Boreham J, Wu YP, Li JY, et al. Emerging tobacco hazards in China: 1. Retrospective proportional mortality study of one million deaths. BMJ 1998; 317: 1411-1422.

53. Lawlor D, Song Y, Sung J, Ebrahim S, Davey Smith G. The association of smoking and cardiovascular disease in a population with low cholesterol levels: a study of 648,346 men from the Korean National Health System prospective cohort study. Stroke (in press).

54. Araujo CL, Victora CG, Hallal PC, Gigante DP. Breastfeeding and overweight in childhood: evidence from the Pelotas 1993 birth cohort study. Int J Obes 2006; 30: 500-506.

55. Hallal PC, Wells JC, Reichert FF, Anselmi L, Victora CG. Early determinants of physical activity in adolescence: prospective birth cohort study. BMJ 2006; 332: 1002-1007.

56. Bobak M, Marmot M. Alcohol and mortality in Russia: is it different than elsewhere? Ann Epidemiol 1999; 9: 335-338.

57. Mckee M, Chenet L. Alcoholism and rising mortality in the Russian Federation. BMJ 1995; 310: 1668-1669.

58. Mckee M. Alcohol in Russia. Alcohol Alcohol 1999; 34: 824-829.

59. Mckee M, Shkolnikov V, Leon DA. Alcohol is implicated in the fluctuations in cardiovascular disease in Russia since the 1980s. Ann Epidemiol 2001; 11: 1-6.

60. Yach D, Cameron N, Padayachee N, Wagstaff L, Richter L, Fonn S. Birth to ten: child health in South Africa in the 1990s. Rationale and methods of a birth cohort study. Paediatr Perinat Epidemiol 1991; 5: 211-233.

61. Richter L, Norris S, Pettifor J, Yach D, Cameron N. Cohort profile: Mandela's children: The 1990 birth to twenty study in South Africa. Int J Epidemiol 2007; 36: 504-511.

62. Richter LM, Norris SA, De Wet T. Transition from birth to ten to birth to twenty: the South African cohort reaches 13 years of age. Paediatr Perinat Epidemiol 2004; 18: 290-301.

63. Wadsworth ME, Butterworth SL, Hardy RJ, Kuh DJ, Richards M, Langenberg $\mathrm{C}$, et al. The life course prospective design: an example of benefits and problems associated with study longevity. Soc Sci Med 2003; 57: 2193-2205.

64. Wadsworth ME, Mann SL, Rodgers B, Kuh DJ, Hilder WS, Yusuf EJ. Loss and representativeness in a 43 year follow up of a national birth cohort. J Epidemiol Community Health 1992; 46: 300-304.

65. Power C, Elliott J. Cohort profile: 1958 British birth cohort (National Child Development Study). Int J Epidemiol 2006; 35: 34-41.
66. Elliott J, Shepherd P. Cohort profile: 1970 British Birth Cohort (BCS70). Int J Epidemiol 2006; 35: 836-843.

67. Smith K, Joshi H. The Millennium Cohort Study. Popul Trends 2002; 30-34.

68. Golding J. The Avon Longitudinal Study of Parents and Children (ALSPAC) - study design and collaborative opportunities. Eur $J$ Endocrinol 2004; 151 (Suppl 3): U119-U123.

69. Leon DA, Lawlor DA, Clark H, Macintyre S. Cohort profile: the Aberdeen children of the 1950s study. Int J Epidemiol 2006; 35: 549552.

70. Olsen J, Melbye M, Olsen SF, Sorensen TI, Aaby P, Andersen AM, et al. The Danish National Birth Cohort - its background, structure and aim. Scand J Public Health 2001; 29: 300-307.

71. Martin LT, Fitzmaurice GM, Kindlon DJ, Buka SL. Cognitive performance in childhood and early adult illness: a prospective cohort study. J Epidemiol Community Health 2004; 58: 674-679.

72. Silva PA. The Dunedin Multidisciplinary Health and Development Study: a 15 year longitudinal study. Paediatr Perinat Epidemiol 1990; 4: 76-107.

73. Martorell R, Habicht JP, Rivera JA. History and design of the INCAP longitudinal study (1969-77) and its follow-up (1988-89). J Nutr 1995; 125: 1027S-1041S.

74. Barros FC, Victora CG, Barros AJ, Santos IS, Albernaz E, Matijasevich $A$, et al. The challenge of reducing neonatal mortality in middle-income countries: findings from three Brazilian birth cohorts in 1982, 1993, and 2004. Lancet 2005; 365: 847-854.

75. Barbieri MA, Bettiol H, Silva AA, Cardoso VC, Simões VM, Gutierrez MR, et al. Health in early adulthood: the contribution of the $1978 / 79$ Ribeirão Preto birth cohort. Braz J Med Biol Res 2006; 39: 1041 1055.

76. Cardoso VC, Simões VMF, Barbieri MA, Silva AAM, Bettiol H, Alves MTSSB, et al. Profile of three Brazilian birth cohort studies in Ribeirão Preto, SP and São Luís, MA. Braz J Med Biol Res 2007; 40: 1165-1176.

77. Kuzawa CW, Adair LS. Lipid profiles in adolescent Filipinos: relation to birth weight and maternal energy status during pregnancy. Am J Clin Nutr 2003; 77: 960-966.

78. Adair LS, Cole TJ. Rapid child growth raises blood pressure in adolescent boys who were thin at birth. Hypertension 2003; 41: 451 456. 